\title{
THE DYNAMICS OF OUTSOURCING MAINTENANCE OF CIVIL INFRASTRUCTURES IN PERFORMANCE BASED CONTRACTS
}

\author{
Schoenmaker $\mathrm{R}^{\mathrm{a}}$, de Bruijn $\mathrm{JA}^{\mathrm{b}}$ and Herder $\mathrm{PM}^{\mathrm{c}}$ \\ ${ }^{a}$ Dept. of Civil Engineering and Geosciences, Delft University of Technology, Delft, Netherlands \\ ${ }^{b}$ Dept. of Technology, Policy and Management, Delft University of Technology, Delft, Netherlands \\ ${ }^{c}$ Dept. of Technology, Policy and Management, Delft University of Technology, Delft, Netherlands
}

\begin{abstract}
An important feature in managing civil infrastructures is the growing use of outsourcing in the delivery of maintenance. It shows a strong increase in the application of performance-based contracts. The expectations of the principals are high: a smaller organization, better service, lower costs, more innovation and more flexibility. But there are also risks connected to performance-based outsourcing of maintenance: the use of the wrong performance requirements, strategic behavior of the contractor and a lack of knowledge and experience of the principal. The main question for the authorities that want to outsource their maintenance is: how do we achieve as much as possible of the expected advantages while limiting the possible disadvantages to a minimum?

This paper answers that question by investigating the strategies that the English Highways Agency and the Dutch Rijkswaterstaat use, when outsourcing the maintenance of their existing road infrastructures and what the effects of their strategies are. Lessons are drawn from the case studies and they are of most interest to other road authorities that consider, or already have chosen, outsourcing the delivery of maintenance as the way forward.
\end{abstract}

Keywords: outsourcing, maintenance, roads, highways, contracting, strategic behavior, performance

\section{INTRODUCTION}

In recent years, outsourcing maintenance of civil infrastructures drew more and more attention of asset owners, asset managers, contractors, politicians and, though more limited, of scholars. Traditionally public organizations, as asset owners, used their own staff for determining and delivering the required maintenance. The public organization used private parties to execute specific, prescribed tasks under direct supervision of public staff. Pressed by institutional reforms, public opinion and limited financial means the public asset owners increasingly collaborate with private parties. Different forms of collaboration appear in varying combinations of design, build, maintain, operate and/or finance. The emphasis lies on using performance-based contracts because of the anticipated advantages that come with steering on outputs. In performance-based contracts, the focus lies on the results the principal wants to achieve and not on specifically mentioning all the required activities. In case of performancebased contracts for maintenance, the goal is to achieve those results, e.g. an available, safe, comfortable road, over a longer period for an existing infrastructure.

The general perception is that greater autonomy of the contractor and stronger links between performance and payment will lead to (cost) advantages for the principal. A critical note here is appropriate. The anticipated advantages of performance-based contracts are compared to the traditional way of contracting, in which the work was specified in much detail. Identifying and quantifying the advantages and determining a causal relation between the way of contracting and the advantages prove difficult [1].

There are not only advantages to performance-based contracting, but also disadvantages and risks, such as opportunistic contractor behavior, or difficulty in specifying the performance. The problem for the principals is, that with the introduction of contracts based on measuring performance, not only the advantages but also the disadvantages and risks will become manifest and the expected advantages will not be gained to full potential. 


\section{RESEARCH QUESTION}

In spite of the difficulties with assessing the real advantages and the associated risks, many asset owners turn to performance-based contracting. Not a great deal of research has been done on the effects and operation of performance-based maintenance contracts and what that means for the governance of those contracts [2-4]. The following question will be explored in this paper:

What tactics are used by public organizations when outsourcing maintenance of existing civil infrastructures to achieve as much as possible of the expected advantages while limiting the possible disadvantages to a minimum?

The next section discusses the concepts of road maintenance, outsourcing, and the combination of outsourcing and performance measurement.

\section{ROAD MAINTENANCE AND ITS COMPLICATING FEATURES}

In this paper, maintenance is defined as: The whole set of activities that are needed for keeping the required function(s) available at the agreed level of service.

In addition to this definition it is essential that maintenance be executed in an efficient and effective way by minimizing risks, restoring and preventing defects and minimizing life cycle costs.

Also of importance is the cyclic nature of maintenance. Based on an existing model [5], a model of the cyclic maintenance process has been developed [6], see figure 1, that is used for analyzing the cases, see paragraph 5.

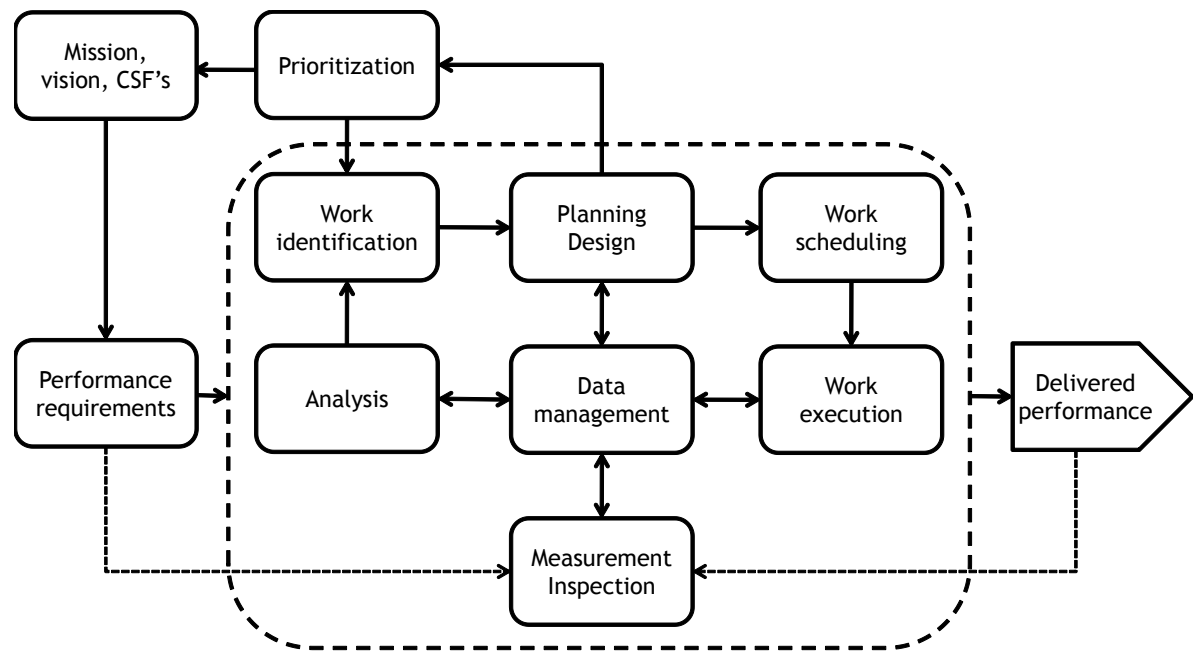

Figure 1. Model of the cyclic maintenance process [6]

The performance requirements that have to be maintained are input to this model, followed by a cyclic process of measurement, analysis, work identification, planning, work preparation and execution. This model is used to consistently describe the degree of outsourcing the maintenance.

Maintenance has a number of complicating features that make the use of performance measurement problematic:

1. The degree of complexity;

2. The degree of autonomy;

3. The degree temporal mismatch;

4. The degree innovation and dynamics;

5. The degree of unknown issues - unknowns, unknowables.

An example of complexity is the interaction of competing performance requirements, giving a choice of alternative measures, like a rapid response at higher costs or a more economic response with more hindrance to the customer. The contractor cannot always act autonomously because third parties are also at work in the same network or the contractor depends on third parties (permits, information, and supply) to be able to deliver. Temporal mismatch will occur when the effects of the maintenance activities will only show after completion of the contract. The dynamics are visible in the changing budgets of the principal, in the requirements (i.e. more emphasis on sustainability or economy) or in the developing technology, making possible news ways of working or even new levels of service. Examples of unknown issues are the costs of finding out the cause of defects and failures, the time and cost needed to repair damage after incidents or the necessity at the time of earlier scheduled maintenance [6].

Generally, the more parts of the maintenance process are outsourced and the more abstract (also multi-valued) the performance requirements are, the larger the influence of the complicating features. Because of these features, the principal will never achieve the full potential of the expected advantages of performance-based contracting. 


\section{THEORETICAL PERSPECTIVES}

Three theoretical perspectives were adopted to explore the workings and difficulties of performance based contracting in road maintenance.

Transaction cost economics: Transaction cost economics studies the most efficient governance structure for a transaction, such as contracts, alliances, hierarchies, etc., by looking at the characteristics of that transaction and assuming bounded rationality and the possibility of opportunistic behavior. Every governance structure has certain costs. Minimizing transactions costs leads to efficient organizational boundaries and a corresponding efficient governance structure $[7,8]$.

Agency theory: The agency theory studies the most efficient form of contract in a principal-agent relationship in different situations of goal congruence, information asymmetry and a difference in risk-aversion between the principal and agent. The principal has a choice of different mitigating measures, each accompanied by a certain cost $[9,10]$.

Performance measurement: When studying performance measurement systems, focus is on designing and applying the process and structure of performance measurement in such a way that the positive effects are promoted and the inherent perverse effects are minimized. Performance measurement systems are never complete: not all aspects of reality will be covered by the measurement system [11, 12].

The theoretical perspectives result in an analytical framework that is used to study the practices in four cases. Elements of the framework are the characteristics of the transaction, of the relation, the incentives and of the process and structure of the performance management system.

\section{CASE STUDY AND CASE PROTOCOL}

The study comprises of a longitudinal study of several cases, by making new combinations from existing sources (contracts, evaluations, reports, audits, etc.). Interviews and expert meetings are used, aimed at validation, explanation and illumination of the information from the written sources.

In order to be able to compare the strategies over a longer period, the research is longitudinal. The following four cases have been studied:

$\begin{array}{lllll}\text { - } & \text { Netherlands: } & \text { Rijkswaterstaat (RWS) } & \text { Performance contracts } & 2004-2008 \text {; } \\ \text { - } & \text { Netherlands: } & \text { Rijkswaterstaat (RWS) } & \text { Pilot contract } & 2007-2010 \text {; } \\ \text { - } & \text { England: } & \text { Highways Agency (HA) } & \text { MA-TMC contract } & 2001-2008 \text {; } \\ \text { - } & \text { England: } & \text { Highways Agency (HA) } & \text { MAC contracts } & \text { 2004-2010. }\end{array}$

The theoretical framework is not usable for a one-on-one description of the reality. Describing and analyzing the 'contracted reality' is done using the research questions mentioned below. The relevant features of the theoretical perspectives will become visible using this operationalization of the analytical framework. The empirical findings are grouped under four themes:

1) Theme: The object that is outsourced

a) physical parts that are maintained and the degree of integration of the various technical disciplines

b) types of maintenance that is part of the outsourcing

2) Theme: The division of roles

a) division of roles in the maintenance process

3) Theme: performance indicators and incentives
a) types of indicators that are used
b) nature of the indicators that are used
c) payment mechanisms are used
d) other, more specific, incentives
4) Theme: Governance

a) governance of the contract

\section{CASE DESCRIPTION AND OBSERVATIONS}

Physical parts: Most contracts comprise nearly all the components of the infrastructure, e.g. gutters, verges, asphalt, bridges, viaducts, lining, rest areas, and signs. Both RWS and HA exclude technical installations for automated traffic management. Winter maintenance is part of the HA contracts, whereas RWS uses separate contracts.

Types of maintenance: RWS primarily includes routine maintenance plus a small amount of periodic maintenance in these contracts. The HA includes all maintenance activities up to a financial threshold.

Division of roles: In RWS cases the contractor has to comply with the performance requirements and no (change or quality) processes are described or prescribed. There is no process approach in the MA-TMC case of the HA. When describing the requirements, the activities are most significant. In the later MAC contracts the primary process is 
prescribed and the contractor has to submit a quality plan based on that process.

Type and nature of the indicators: RWS only uses product indicators (output) linked to the quality of the infrastructure, but not indicators that are linked to the overall goals of RWS. The HA uses input, throughput and output indicators for product and non-product indicators, e.g. for cost and collaboration. The HA has put in a lot of effort in developing a performance management system that links the multi-valued goals and the activities needed to achieve those goals.

Payment mechanism: RWS uses a fixed payment for the routine maintenance as a whole and for each maintenance activity that is ordered separately. The HA uses three payment mechanisms: fixed price, hourly rates and target prices.

Other incentives: Both principals initially used lane rental, but abandoned that principle due to safety issues. RWS used fines in the first case, but not in the second case. The HA does not use fines, but uses penalty points in case of shortcomings. Those penalty points will lead to extra audits, at the cost of the contractor. In all cases there is the possibility of extending the contract.

The HA uses past performance as an incentive for good (present) performance, by using the present performance (by then past) as an important factor when selecting candidates for future tenders.

Governance: Both RWS and HA changed from direct supervision to governance based on the quality management system of the contractor. The RWS prestatiebestek is awarded on price only, the pilot contract on price/quality criteria. The HA uses that principle in both cases. Additionally the HA uses an instrument to measure process maturity of the contractor in the selection phase of the tender procedure. The HA emphasizes its partnering principles and pays a lot of attention to community building. RWS introduces the partnering principles in the pilot contract; the concept of community building is missing at RWS.

\section{CASE STUDY RESUlTS: CORE PROBLEMS, EFFECTS AND COMPARISON}

The observations and findings briefly discussed in the previous section have been analyzed from each theoretical perspective, using the following set of questions: 1) What is the core problem as seen from the theoretical perspective?; 2) What effects become manifest in the contracts studied?; 3) What are differences in tactics between the cases in dealing with the core problem?; and 4) What is the most efficient tactic according to each theoretical perspective?

Core problems: From each of the three theoretical perspectives, a core problem is identified. The characteristics of the (maintenance) transaction lead to 'serious contracting difficulties' and according to the transaction cost economics the core problem is uncertainty about (past and) future contingencies. Changes will always occur. Information asymmetry is the core problem according to the agency theory. The goals of the principal and agent are not congruent and the principal is not fully informed about the behavior of the agent. The way of contracting needs to match that. The possibility of perverse effects of performance measurement is the third core problem. The multiple (and multi-valued) goals of the principal and the complicating features of maintenance and performance measurement make outsourcing problematic.

Effects: In all four cases, contracting difficulties are apparent, regardless of the approach used by the principal. This is proof of the persistent character of the perverse effects. The cases are rich in examples showing the effects that appear when the principal turns to outsourcing based on performance requirements, implementing an, until then not yet defined, approach to mitigate the contracting difficulties. In all cases governance was considered to have room for improvement by the respective national audit offices [13, 14].

A few examples: suboptimization because of the short term focus of the contractor based on the performance indicators, cherry picking when proposing maintenance interventions, lack of ambition when measures are easily met, insufficient contract management leading to invoices being paid without proper checking, etc.

Comparison of the approaches: RWS and HA have adopted clearly different approaches for dealing with the contractual difficulties. RWS opts for ex-ante completeness, for maintaining a certain distance to the contractor and for performance measurement that is solely used for measuring contract compliance. The HA opts for ex-post flexibility, interaction and performance measurement that is, apart from the inevitable contract-compliance, mainly used for continual improvement, see table 1.

Table 1

Approaches for dealing with contractual difficulties

\begin{tabular}{llll}
\hline Theory & Core problem & Rijkswaterstaat & Highways Agency \\
\hline Transaction cost & Uncertainty & Ex-ante completeness & Ex-post flexibility \\
Agency theory & Info-asymmetry & Distance philosophy & Interaction, participation \\
Performance mgt. & Perverse effects & Focus on compliance & Focus on improvement \\
\hline
\end{tabular}




\section{MOST EFFICIENT APPROACH BASED ON THEORETICAL PERSPECTIVES}

In due course both RWS and HA have moved to more abstract performance measures with, as a consequence, a growing influence of the complicating features of maintenance and performance measurement. This logically leads to a number of inevitabilities. According to the transaction cost economics the characteristics of the transaction (relation) for the HA (already to a great extent) and for RWS (to an increasing extent) demand a hybrid governance structure with ex-post negotiation. Decisions about future contingencies are taken during the course of the contract instead of at the outset. The essential components of a hybrid arrangement are:

- Classic contracting for performance measures that are less ambiguous and/or lead to activities with a predictable, repetitive character;

- Bilateral governance performance measures that are more ambiguous and/or lead to activities that are less predictable and a have a less repetitive character;

- Specific, agreed processes for dealing with the bilateral aspects of the governance.

The governance of such hybrid contracts thus consists of:

- $\quad$ Output steering linked with payment based on results;

- $\quad$ Input steering linked with payment based on effort;

- $\quad$ Input steering with programmed tasks and payment based on completed tasks;

- A division in the decision-making process, giving the principal influence on the choices the agent is making (proposing).

The performance measurement system calls for (ex-post) interaction and a partial decoupling of payment and performance (achievement). The interaction will lead to more trust of the contractor in the performance measurement (use and review). The partial decoupling of payment and performance (achievement) moderates the performance measurement and decreases the propensity towards strategic behavior.

\section{CONCLUSION: SUGGESTIONS FOR IMPLEMENTING THE MOST ADEQUATE APPROACH}

When taken to a more operational level, the most efficient approaches according to theory can be described as suggestions for implementing the most adequate approach:

1. Adjust the governance to the degree of uncertainty;

Only part of all performance requirements will lead to predictable maintenance activities that can be planned years ahead. For those requirements the entire maintenance process can be outsourced. When uncertainties begin to play a bigger role, a more intelligent process is needed. The essence of the intelligent process is a division in the maintenance process (see figure 1). The principal (i.e. asset manager) demands maintenance proposals from the contractor. The principal decides whether or not to implement those proposals. It is the obligations of the contractor to timely propose the maintenance activities in order to (enable the principal to) comply with all of the multi-valued goals.

2. Provide nearness between actors and sharing of information

The intelligent process requires the sharing of information and the nearness of those involved. The sharing of information and the nearness of the actors have to be stimulated. Firstly by using performance measurement in a less coercive way than for contract compliance only. Secondly by facilitating physical nearness of the actors through integrated teams and shared offices. Thirdly by having community building contribute to mutual understanding and trust and making that community the place for joint development and improvement of processes.

3. Provide incentives for collaborative behavior

The uses of the shadow of the near future and the shadow of the far future have proven to be effective in the cases. The shadow of the near future is the outlook for more work during this contract. The shadow of the far future is the outlook for more work after this contract, based on the present performance during this contract. Good performance increases the chance of success 'there and later'. A third incentive is linked to the audits of the quality management system of the contractor. Positive results from audits can be used to award the contractor with a lighter audit regime. And vice versa.

\section{Put demands on the competencies of the outsourcing organizations}

Outsourcing organizations have to be able to design and fine-tune the intelligent process and to manage the process at the interface with the contractor. This intelligent process requires a more complex management than when staying remote from the contractor, and it requires an informed en knowledgeable principal. The points mentioned under (2) should benefit becoming an informed principal. They have to reduce the information asymmetry between principal and contractor. As a consequence, the principal has to able to give a sensible meaning to the acquired information, hence the need for the principal to be knowledgeable and be able to take the right decisions. 


\section{REFERENCES}

1. Anastasopoulos, P.C., et al., A Cost Savings Analysis of Performance-based Contracts for Highway Maintenance Operations. Journal of Infrastructure Systems, 2009(Posted ahead of print).

2. NCHRP, Performance-based contracting for maintenance, in NCHRP synthesis. 2009, Transportation Research Board: Washington, D.C.

3. Pakkala, P.A., W.M. de Jong, and J. Äijö, International Overview Of Innovative Contracting Practices For Roads. 2007, Finnish Road Administration: Helsinki.

4. Altamirano, M.A., Innovative Contracting Practices in the Road Sector. 2010, Technische Universiteit Delft: Delft. p. 384.

5. Murthy, D.N.P. and K.A.H. Kobbacy, Complex system maintenance handbook. Springer series in reliability engineering. 2008, London: Springer. xi, 657 p.

6. $\quad$ Schoenmaker, R., The Chosen Way (org. title: De ingeslagen weg). 2011, Delft University of Technology: Delft.

7. Williamson, O.E., The Economic Institutions of Capitalism. 1985, New York: The Free Press.

8. Milgrom, P.R. and J. Roberts, Economics, organization, and management. 1992, Englewood Cliffs, N.J.: Prentice-Hall. xvii, $621 \mathrm{p}$.

9. Fama, E.F. and M.C. Jensen, Separation of Ownership and Control. Journal of Law and Economics, 1983. 26(2): p. 301-325.

10. Eisenhardt, K.M., Agency Theory - An Assessment and Review. Academy of Management Review, 1989. 14(1): p. 57-74.

11. de Bruijn J. A., Managing Performance in the Public Sector. 2007, London Routledge.

12. Meyer, M.W., Rethinking performance measurement : beyond the balanced scorecard. 2002, Cambridge, UK ; New York: Cambridge University Press. xiv, 202 p.

13. National Audit Office, Highways Agency Contracting for Highways Maintenance. 2009, The Stationery Office: London.

14. Algemene Rekenkamer, Rapport bij het jaarverslag 2009 van Ministerie van Verkeer en Waterstaat (XII), in Tweede Kamer, vergaderjaar 2009-2010, 32360 XII, nr. 2. 2010: 's-Gravenhage. 